\title{
Full-Service Family Practice in British Columbia: Policy Interventions and Trends in Practice, 1991-2010
}

\section{Cliniques familiales offrant des services intégraux en Colombie-Britannique : interventions politiques et tendances de la pratique, 1991-2010}

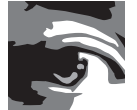 \\ M. RUTH LAVERGNE, MSC \\ Graduate Student, Centre for Health Services and Policy Research \\ School of Population and Public Health, Faculty of Medicine \\ University of British Columbia \\ Vancouver, BC \\ SANDRA PETERSON, MSC \\ Analyst, Centre for Health Services and Policy Research \\ University of British Columbia \\ Vancouver, BC \\ RACHAEL MCKENDRY, MA \\ Research Coordinator, Centre for Health Services and Policy Research \\ University of British Columbia \\ Vancouver, BC \\ SASKIA SIVANANTHAN, MSC \\ Graduate Student, Centre for Health Services and Policy Research \\ University of British Columbia \\ Vancouver, BC \\ KIMBERLYN MCGRAIL, MPH, PHD \\ Associate Professor, Centre for Health Services and Policy Research \\ University of British Columbia \\ Vancouver, BC
}


Full-Service Family Practice in British Columbia: Policy Interventions and Trends in Practice, 1991-2010

\begin{abstract}
Background: British Columbia's primary care reform (initiated in 2002) aims to promote "full-service family practice" through incentive payments and other practice support programs. Despite attention to policy, no longitudinal analysis has been conducted of the activities of $\mathrm{BC}$ primary care physicians.

Methods: This study employed linked administrative health data from 1991/92 through $2009 / 10$ to describe dimensions of care from the definition of "full-service family practice" used in BC reform, grouped into four categories: access, continuity, coordination and comprehensiveness.

Results: Access, continuity and coordination of care fell over the study period $(p<0.001)$. Some dimensions reflecting comprehensiveness of care declined (obstetrics and geriatric care), though the remainder did not change significantly. Overall declining trends were consistent across physician characteristics and remained significant when accounting for shifts to nonfee-for-service payment.

Conclusion: Findings suggest efforts are not achieving their intended aims. Rigorous evaluation of individual components of reform is needed.
\end{abstract}

\title{
Résumé
}

Contexte : La réforme des soins de santé primaires en Colombie-Britannique (amorcée en 2002) vise la promotion de « cliniques familiales offrant des services intégraux » par le biais de primes d'incitation et autres programmes de soutien aux cliniques. Malgré l'attention portée à la politique, il n'y a eu aucune analyse longitudinale sur les activités des médecins de première ligne en Colombie-Britannique.

Méthodes : Cette étude fait appel à des données administratives sur la santé de 1991/1992 à 2009/2010 afin de décrire les aspects des soins au regard de la définition des « cliniques familiales offrant des services intégraux » utilisée dans le cadre de la réforme en ColombieBritannique, et ce, en fonction de quatre catégories : accès, continuité, coordination et intégralité.

Résultats : Laccès, la continuité et la coordination des soins ont diminué au cours de la période étudiée $(p<0,001)$. Certains aspects liés à l'intégralité des soins ont décliné (soins obstétriques et gériatriques), bien que les autres naient pas connu de changements significatifs. Les tendances générales du déclin sont cohérentes par rapport aux caractéristiques des médecins et demeurent significatives si on tient compte des déplacements vers des méthodes de paiement qui ne fonctionnent pas à l'acte.

Conclusion: Les résultats laissent croire que les efforts ne permettent pas d'atteindre les objectifs visés. Il y a grand besoin d'une évaluation rigoureuse des diverses composantes de la réforme. 
$\mathrm{P}$ RIMARY CARE PLAYS A FUNDAMENTAL ROLE IN THE PROVISION OF HEALTHCARE and has been linked to better outcomes for patients, equity within populations and efficiency in health systems (Starfield et al. 2005). Despite this understanding, longstanding concerns persist about access to high-quality, comprehensive primary care in Canada (Starfield 2008). While the supply of general practice physicians per capita has been relatively stable (CIHI 2012), doctors report that they are providing fewer hours of direct patient care (Crossley et al. 2009; Watson et al. 2006); young doctors especially report seeking improved work-life balance (CMA Bulletin 2011). At the same time, the comprehensiveness of family practice appears to have declined as doctors abandon specific areas (such as obstetrics, anaesthesia or provision of services in hospitals, homes and long-term care facilities) (Chan 2002; Wong and Stewart 2010). The trend towards walk-in clinics has also aroused concern (Tregillus and Cavers 2011).

Provinces are taking varying approaches to improve provision of primary care. Reforms in several provinces emphasize changing the structure and organization of primary care, encouraging physicians to move to allied health teams or community clinic models of practice. Changes from fee-for-service to salaried, capitation or blended models of payment often accompany these structural reforms (Hutchison et al. 2011).

Reform in British Columbia has sought neither to introduce or support new models of care provision, nor to support an expanded role for non-physician care providers. Leaders of the reform efforts wrote: "At the heart [of the BC approach] was the conviction that the doctor-patient dyad - the trust-based long-term relationship forged over time - is the critical attribute of a successful primary healthcare system" (Tregillus and Cavers 2011). A teambased approach was rejected based on the rationale that practising GPs were not trained for this model, and that it may be difficult to apply in regions with sparse populations and shortages in healthcare human resources (Tregillus and Cavers 2011). Beginning in 2002, British Columbia introduced a number of programs to support family physicians in their existing practices, including a suite of incentive payments (Cavers et al. 2010). Fee-for-service remains the predominant payment model.

Reform is being led by the BC General Practice Services Committee, established in 2002 with a mandate "to support the provision of full-service family practice and improve patient care" (GPSC 2009). The GPSC is a joint committee of the BC Ministry of Health, the BC Medical Association and the Society of General Practitioners of British Columbia, with representatives from the province's health authorities attending meetings as guests. By far the largest investment as part of reform is the suite of new incentives for primary care physicians rolled out between 2003 and 2008, including payments for obstetrics, mental health, management of chronic and complex conditions, care for the frail and elderly and palliative care. It is estimated that these payments increased the annual incomes of participating GPs by $\$ 27,000$ on average (GPSC 2012; Tregillus and Cavers 2011). In addition to incentive payments, the GPSC implemented programs aimed at improving support for physicians in their existing practices. Networks of community-based physicians are forming as Divisions of Family 
Full-Service Family Practice in British Columbia: Policy Interventions and Trends in Practice, 1991-2010

Practice, intended to provide a strong collective voice, and forums for coordinated work on local healthcare priorities. The Practice Support Program, launched in April 2007, provides training and resources with learning modules on topics including practice management, mental healthcare and end-of-life care (Cavers et al. 2010; Mazowita and Cavers 2011; Tregillus and Cavers 2011).

British Columbia's approach to reform has been called "operational" rather than "structural" (Tregillus and Cavers 2011) in that it maintains the existing fee-for-service remuneration system without either forcing or encouraging structural change through new models of service provision or remuneration. Incentives are the most expensive component of this approach, but are not the only focus. The idea was that the whole suite of reforms the GPSC put in place would work together to increase the extent to which primary care physicians provide full-service care.

In documentation supporting the Full-Service Family Practice Incentive Program, the GPSC defines full-service family practice as a style of practice that includes most, if not all, of the dimensions outlined in Table 1 (GPSC and BC Ministry of Health 2010; Mazowita and Cavers 2011).

TABLE 1. Dimensions of full-service family practice as outlined by the GPSC

\begin{tabular}{|c|c|}
\hline Dimension & Description \\
\hline Health assessments* & Health and health-risk assessment \\
\hline Coordination & $\begin{array}{l}\text { Coordination of patient care across the spectrum of primary, secondary and tertiary care, including making } \\
\text { referrals and acting upon consultative advice }\end{array}$ \\
\hline Continuity & Longitudinal care of patients across the spectrum of their medical needs \\
\hline $\begin{array}{l}\text { Services for acute and chronic } \\
\text { conditions }\end{array}$ & $\begin{array}{l}\text { Diagnosis and management of acute ailments; chronic disease management, including implementation of } \\
\text { BC guidelines }\end{array}$ \\
\hline Reproductive care & Primary reproductive care, including the organization of appropriate screening \\
\hline Maternity care & $\begin{array}{l}\text { The provision of or the arrangement with another provider for prenatal, obstetrical, postnatal and } \\
\text { newborn care }\end{array}$ \\
\hline Mental healthcare & Primary mental healthcare \\
\hline Palliative care* & Primary palliative care \\
\hline Geriatric care & Care and support of the frail elderly \\
\hline Services in alternative settings & Support for hospital, home, rehabilitation and long-term care facilities \\
\hline Education and prevention & Patient education and preventive care \\
\hline Record keeping* & The maintenance of a longitudinal patient record \\
\hline Access outside office hours & $\begin{array}{l}\text { An association with other practitioners that assigns patients a designated provider to contact for medical } \\
\text { advice and/or care as appropriate, both during and outside office hours; an association that includes the } \\
\text { use of call-group guidelines and protocols for patient follow-up }\end{array}$ \\
\hline IT* & $\begin{array}{l}\text { The future use of information technology systems as they become available to enhance the coordination } \\
\text { and provision of patient care }\end{array}$ \\
\hline
\end{tabular}

* Not measured in this paper 
At this time, we have no information on whether provision of care reflecting these dimensions changed over the period leading up to or encompassing the suite of reform efforts (beginning in 2002). In fact, despite considerable attention to primary care policy across Canada, little in the literature describes changes in the activities of primary care physicians over time. Research has described primary care physician practice cross-sectionally using surveys (Haggerty 2008; Hutten-Czapski et al. 2004; Wong and Stewart 2010) and administrative data (Glazier et al. 2009; Olatunde et al. 2007), and considerable progress has been made in the development of instruments to prospectively measure attributes of primary care (Burge et al. 2011; J. Haggerty et al. 2007). However, studies examining practice patterns over time have been more limited, using administrative data to measure comprehensiveness of services provided but not other important functions of primary care, namely, maintaining continuity and coordination of care (Chan 2002; Kazanjian et al. 2000).

This study begins to fill this gap. Using population-based and provider-specific administrative data, we operationalize dimensions of full-service family practice - the overarching target of the GPSC's reforms, as defined and promoted by the BC Medical Association and Ministry of Health Services (GPSC and BC Ministry of Health 2010). We then describe provision of healthcare services reflecting these dimensions before, during and after reform efforts, and by physician characteristics.

\section{Methods}

\section{Conceptual framework for the analysis}

Starfield describes primary care services as having four main features: first-contact access, long-term continuity (focused on the person, not disease), coordination of care among providers and comprehensiveness for most health needs (Starfield 1998). While the GPSC did not use Starfield's framework when defining the full-service family practice dimensions outlined in Table 1, there is a clear fit between the two. Because Starfield's framework has international acceptance as a way to describe primary care, we used it to help give context to the GPSC reforms and subsequently to measure these different aspects of primary care over time.

We determined that we could use British Columbia's administrative data for longitudinal measurement of 10 of the 14 dimensions outlined in Table 1 . These 10 are outlined and organized into the Starfield framework in Table 2. The four dimensions not measured were health assessments, record keeping, information technology and palliative care. Providing health and health-risk assessments, including history taking, physical exam and diagnostic evaluation, are key activities of primary care physicians as first-contact care providers. While we assumed these activities to be a basic element of patient visits, we could not measure them directly. All practices keep records for billing purposes, but maintenance of a detailed and complete longitudinal record is likely variable and could not be evaluated using administrative data. Use of information technology is similarly variable and not captured in administrative data. Palliative care could not be measured because only a small subset of decedents receive specialized care that corresponds to unique fee codes, and these have changed over the study period. Finally, while prevention activities were measured using screening activities, patient 
Full-Service Family Practice in British Columbia: Policy Interventions and Trends in Practice, 1991-2010

education could not be measured. The GPSC has introduced incentives to support risk assessment and education, but as these activities would previously have been billed as general visits or counselling, it is not possible to track them over time.

TABLE 2. Measurement of full-service family practice using BC administrative data

\begin{tabular}{|c|c|c|}
\hline Dimensions* & Measurement using administrative data & Scoring \\
\hline \multicolumn{3}{|c|}{ First-contact access for each new need } \\
\hline Access outside office hours & $\begin{array}{l}\text { Provision outside office hours is measured using specific fee codes. } \\
\text { There are no data on call groups, but we assumed members of call } \\
\text { groups would have some provision of service outside office hours. }\end{array}$ & $\begin{array}{l}\text { Services outside } \\
\text { office hours }=100 \\
\text { No such services }=0\end{array}$ \\
\hline Services in alternative settings & $\begin{array}{l}\text { The number of different settings (hospital emergency department, } \\
\text { other hospital, home, long-term care facilities) in which care was } \\
\text { provided to any patients was recorded based on fee codes. }\end{array}$ & $\begin{array}{l}\text { Office only }=0 \text {, } \\
25 \text { per setting } \\
\text { (All four }=100 \text { ) }\end{array}$ \\
\hline \multicolumn{3}{|c|}{ Continuity - Long-term person-focused care } \\
\hline Continuity & $\begin{array}{l}\text { Percentage of total patients seen in the study year to whom the } \\
\text { physician was major source of care (MSOC), providing 50\% or } \\
\text { more of primary care contacts }\end{array}$ & $0-100$ \\
\hline \multicolumn{3}{|l|}{ Coordination and referral } \\
\hline Coordination & $\begin{array}{l}\text { Percentage of total patients seen in the study year who saw fewer } \\
\text { than four other individual GPs (for outpatient care only) }\end{array}$ & $0-100$ \\
\hline \multicolumn{3}{|c|}{ Comprehensive for most health needs } \\
\hline $\begin{array}{l}\text { Services for acute and chronic } \\
\text { conditions }\end{array}$ & $\begin{array}{l}\text { We classified care as acute or chronic using Johns Hopkins } \\
\text { Aggregated Diagnosis Groups. We report the ratio of acute/chronic } \\
\text { care (lower divided by higher, multiplied by 100). A score closer to } \\
100 \text { indicates more equal provision of acute and chronic care. }\end{array}$ & $0-100$ \\
\hline Reproductive care & $\begin{array}{l}\text { Percentage of women aged I } 8-74 \text { provided Pap testing in study } \\
\text { year, based on fee codes (multiplied by } 3 \text {, as not indicated annually) }\end{array}$ & $0-100$ \\
\hline Maternity care & $\begin{array}{l}\text { We used fee codes to determine whether physicians provided } \\
\text { pre- or postnatal care, or both provided such care and supported } \\
\text { delivery }\end{array}$ & $\begin{array}{l}\text { No maternity care }=0, \\
\text { Pre/post only }=50, \\
\text { Pre/post and delivery }=100\end{array}$ \\
\hline Geriatric care & $\begin{array}{l}\text { Physician provided two-thirds or more of primary care contacts to } \\
\text { patients ages } 75+\text { who received a minimum of } 3 \text { contacts }\end{array}$ & $Y_{e s}=100, \mathrm{No}=0$ \\
\hline Mental healthcare & $\begin{array}{l}\text { Provision of mental health services to any patients, as determined } \\
\text { by ICD codes (290-319) }\end{array}$ & $Y_{e s}=100, \mathrm{No}=0$ \\
\hline Education and prevention & $\begin{array}{l}\text { Average percentage of adults aged } 45+\text { receiving glucose and } \\
\text { lipid testing, based on fee codes (multiplied by } 3 \text {, as not indicated } \\
\text { annually). Education could not be measured directly. }\end{array}$ & $0-100$ \\
\hline
\end{tabular}

Note: Dimensions from the GPSC's definition of full-service family practice (GPSC and BC Ministry of Health 20 I0), organized using elements of primary care outlined by Starfield (1998). More details on measurement, including specific fee codes used, are in Lavergne et al. 2013.

All dimensions were measured on a scale from 0 through 100 (Table 2). We calculated a composite summary score with equal weighting $(0.25)$ for each of Starfield's four features of primary care (first-contact access, long-term continuity, coordination of care among providers and comprehensiveness) in order to make comparisons across time and physician characteristics. Starfield provided a broader framework for measurement, as simply tallying scores across the 10 measures would mean that comprehensiveness of care would dominate 
(because there are multiple dimensions), even though it is only one of four features of primary care. Resulting summary scores also range from 0 through 100 , where 0 means the physician's practice included none of the dimensions of full-service family practice. Alternative weighting schemes were explored in sensitivity analysis, and observed changes in summary scores remained significant. Additional details on the measurement of each dimension, including specific fee codes used, are summarized in an online working paper (Lavergne et al. 2013).

\section{Data sources and study population}

We used British Columbia’s Medical Services Plan (MSP) physician payment files for fiscal years 1991/92, 1996/97, 2001/02, 2004/05 and 2009/10, linked to patient registry files containing demographic information for all persons eligible to receive publicly funded healthcare services through MSP (British Columbia Ministry of Health 2012, 2013a, 2013b). The period begins with the earliest available consistently coded data (1991/92) and ends with the most recent available data. The study period also includes years before (1991/92 through 2001/02), during (2004/05) and after (2009/10) major reform efforts (2002-2008, though some changes are ongoing).

We obtained data on physician demographics, practice location, location of training and specialty from the College of Physicians and Surgeons of British Columbia. All files are maintained by the BC Ministry of Health and were linked and accessed through Population Data BC. Unique, study-specific codes for both patients and physicians enabled detailed analysis without the possibility of identification of specific individuals. Study variables were developed from patient-level data, but all analyses were conducted at the physician level. We removed the effect of fee changes over this period by valuing services provided in all years at the fee levels in effect on April 1, 2005, yielding fee-adjusted expenditures. The UBC Behavioural Research Ethics Board provided approval for this research.

We examined all family or general practice physicians registered with the BC College of Physicians and Surgeons in each of the study years (3,726 in 1991/92, increasing to 5,176 in 2009/10). Some of the analysis relies on counting contacts between patients and physicians. For our purposes, a "contact" is defined as a unique physician/patient/date combination, regardless of how many services were provided on that day. Telephone calls, completion of documentation/forms and other indirect patient care that would not involve an in-person meeting were not included when determining contacts (telemedicine consultations by primary care providers were not funded during the period of our study). Because British Columbia has no formal rostering of patients with physicians, we considered patient attachment to physicians in three ways. First, we counted all unique patients seen over the course of a year, regardless of number of times or the number of other physicians those patients saw. Counts of patients for whom a physician was the "majority source of care" (MSOC) required the physician to provide half or more of the primary care contacts received by the patient in question. Patients with only one contact are assigned an MSOC, but patients with an equal number of contacts from more than one physician cannot be assigned. Counts of patients for whom a 
Full-Service Family Practice in British Columbia: Policy Interventions and Trends in Practice, 1991-2010

physician was the "usual provider of care" (UPC) required patients to have had a minimum of three contacts in the year and for that physician to have provided a minimum of two-thirds of those primary care contacts.

We excluded physicians without billings in every quarter (who may be entering or leaving practice, $n=703$ in 2009/10; see Appendix for complete counts), those with more than 15,000 annual patient contacts (corresponding to more than 60 patients per day, 250 days per year, $\mathrm{n}=53$ ), those with more than $50 \%$ of contacts with known location in hospital (who may be hospitalists, $\mathrm{n}=569$ ), those billing alternative payment plan shadow billing codes (for whom we are missing some amount of patient service activity in the fee-for-service data, $\mathrm{n}=57$ ) and those with less than $\$ 50,000$ in annual billings (which may include physicians receiving supplementary income through salary or sessional arrangements, $n=355$ ). We undertook sensitivity analyses to ensure that these exclusions did not account for changes observed over time (described below).

\section{Analysis}

We calculated scores by both year and physician characteristics. We report average annual change and the $p$-value for the trend over time (based on Pearson's correlation). We used ANOVA to determine whether scores varied according to physician characteristics (reported here for 2009/10 data only).

An increasing percentage of $\mathrm{BC}$ physicians are being paid through alternative payment plans (APPs). Exclusion criteria were designed to remove these individuals from analysis, as the services they provide are not fully captured in fee-for-service data. One possible threat to the validity of the findings is that "full-service" physicians have differentially moved to APPs, resulting in a decline in scores among physicians retained in analysis (but no actual change to the services received by $\mathrm{BC}$ residents). To investigate whether this factor might have influenced our results, we performed a simple but conservative sensitivity analysis. We re-calculated changes in scores with the very strong assumptions that (a) all physicians excluded with APP billings or low billings and (b) all physicians excluded for any reason would have had scores of 100 (see Appendix 1 at www.longwoods.com/content/23782).

\section{Results}

The total number of physicians included in the analysis increased from 2,732 in 1991/92 to 3,429 in 2009/10. Consistent with the introduction of incentives as part of reform, total (2005/06 constant-dollar) payments increased to $\$ 223,708$ in 2009/10 from $\$ 204,503$ in 2001/02, while the number of contacts fell slightly in 2009/10 (Table 3). The number of unique patients seen by each physician was highest in the most recent decade, though the number of patients to whom physicians were usual provider or majority source of care decreased over time. The proportion of female physicians increased, while the percentage of physicians aged 44 and under decreased. Graduates of international medical schools increased as a percentage of total primary care physicians. 
M. Ruth Lavergne et al.

TABLE 3. Characteristics of BC primary care physicians over the study period

\begin{tabular}{|c|c|c|c|c|c|}
\hline & $1991 / 92$ & $1996 / 97$ & $2001 / 02$ & $2005 / 06$ & $2009 / 10$ \\
\hline n (\# physicians included) & 2,732 & 3,190 & 3,189 & 3,201 & 3,429 \\
\hline \multicolumn{6}{|c|}{ Physician practice characteristics (mean, SD) } \\
\hline Total billings (\$) & $\begin{array}{l}209,946 \\
(82,717)\end{array}$ & $\begin{array}{l}202,950 \\
(79,733)\end{array}$ & $\begin{array}{l}204,503 \\
(85,117)\end{array}$ & $\begin{array}{l}209,292 \\
(90,927)\end{array}$ & $\begin{array}{l}223,708 \\
(105,002)\end{array}$ \\
\hline Total \# of contacts & $5,858(2,417)$ & $5,786(2,47 \mid)$ & $5,925(2,627)$ & $6,035(2,832)$ & $5,77 \mid(2,837)$ \\
\hline \# unique patients & ।,83। (867) & $2,017(1,112)$ & $2,086(1,184)$ & $2,175(1,305)$ & $2,154(1,321)$ \\
\hline $\begin{array}{l}\text { \# patients receiving }>50 \% \text { of } \\
\text { primary care }(\mathrm{MSOC})^{\dagger}\end{array}$ & $754(754)$ & $718(718)$ & $716(716)$ & $698(698)$ & $673(435)$ \\
\hline $\begin{array}{l}\text { \# patients receiving }>2 / 3 \text { of } \\
\text { primary care* (UPC) }\end{array}$ & $467(467)$ & $427(427)$ & $428(428)$ & $417(4 \mid 7)$ & $399(309)$ \\
\hline \multicolumn{6}{|l|}{ Physician demographics (n, \%) } \\
\hline Female & $629(23.0)$ & $897(28.1)$ & $956(29.8)$ & ।,018 (31.3) & ।, $178(34.3)$ \\
\hline \multicolumn{6}{|l|}{ Age group } \\
\hline$<40$ & ।,081 (39.6) & $1,110(34.8)$ & $815(25.4)$ & $570(17.5)$ & $507(14.7)$ \\
\hline $40-44$ & $546(20.0)$ & $59 \mid(18.5)$ & $583(18.2)$ & $556(17.1)$ & $386(11.2)$ \\
\hline $45-49$ & $444(16.3)$ & $570(17.9)$ & $563(17.5)$ & $583(17.9)$ & $598(17.4)$ \\
\hline $50-54$ & $218(8.0)$ & $437(13.7)$ & $529(16.5)$ & $537(16.5)$ & $591(17.2)$ \\
\hline $55-59$ & $201(7.4)$ & $197(6.2)$ & $392(12.2)$ & $494(15.2)$ & $530(15.4)$ \\
\hline $60-64$ & $143(5.2)$ & $161(5.1)$ & $162(5.1)$ & $307(9.4)$ & $453(13.2)$ \\
\hline $65+$ & $99(3.6)$ & $123(3.9)$ & $166(5.2)$ & $203(6.2)$ & $374(10.9)$ \\
\hline \multicolumn{6}{|l|}{ Years in practice } \\
\hline$<5$ & $404(14.8)$ & $307(9.6)$ & $159(5.0)$ & $95(3.0)$ & $107(3.1)$ \\
\hline $6-10$ & $437(16.0)$ & $613(19.2)$ & $422(13.1)$ & $292(9.1)$ & $273(7.9)$ \\
\hline $11-20$ & ।,000 (36.6) & ।,047 (32.8) & I, I20 (34.9) & $1,073(33.5)$ & $890(25.9)$ \\
\hline $21-30$ & $540(19.8)$ & $842(26.4)$ & $975(30.4)$ & $970(30.2)$ & ।,088 (31.6) \\
\hline $31+$ & $350(12.8)$ & $379(11.9)$ & $534(16.6)$ & $777(24.2)$ & ।,081 (31.4) \\
\hline \multicolumn{6}{|l|}{ Place of graduation } \\
\hline UBC & $936(34.3)$ & $1092(34.2)$ & $1097(34.2)$ & $1035(32.3)$ & $1,054(31.2)$ \\
\hline Other Canadian medical school & I, $109(40.6)$ & ।,326 (41.6) & ।,308 (40.8) & ।,273 (39.7) & ।,277 (37.8) \\
\hline International medical school & $687(25.2)$ & $77 \mid(24.2)$ & $805(25.1)$ & $900(28.1)$ & $1,049(31.0)$ \\
\hline \multicolumn{6}{|l|}{ Health authority } \\
\hline Vancouver Coastal & $462(17.0)$ & $549(17.3)$ & $562(17.6)$ & $613(18.9)$ & $661(19.2)$ \\
\hline Fraser Health & $698(25.7)$ & $853(26.9)$ & $864(27.1)$ & $882(27.2)$ & $916(26.7)$ \\
\hline Vancouver Island & $823(30.3)$ & $934(29.5)$ & $914(28.7)$ & $889(27.5)$ & $911(26.5)$ \\
\hline Interior & $552(20.3)$ & $637(20.1)$ & $657(20.6)$ & $649(20.0)$ & $735(21.4)$ \\
\hline Northern & $|8|(6.7)$ & 198 (6.2) & 189 (5.9) & 205 (6.3) & $211(6.1)$ \\
\hline
\end{tabular}

† Majority Source of Care (MSOC): Physician provided 50\% or more of primary care contacts to the patient in question. Patients with an equal number of contacts from two or more physicians cannot be assigned.

* Usual Provider of Care (UPC): Physician provided two-thirds or more of primary care contacts. Patients must have a minimum of three contacts in the study year

Note: Data were missing for some physician characteristics. Sex: I missing in 2009/10. Age: I missing in 2005/06. Years in practice: I missing in 1991/92 and 200 I/02, 44 in 2005/06. Place of graduation: 43 missing in 2005/06, 59 in 2009/10. Health authority: 16 missing in 199|/92, 18 in 1996/97, 24 in 2001/02, 13 in 2005/06 and 5 in 2009//0. 
Full-Service Family Practice in British Columbia: Policy Interventions and Trends in Practice, 1991-2010

TABLE 4. Change in dimensions of full-service family practice over time

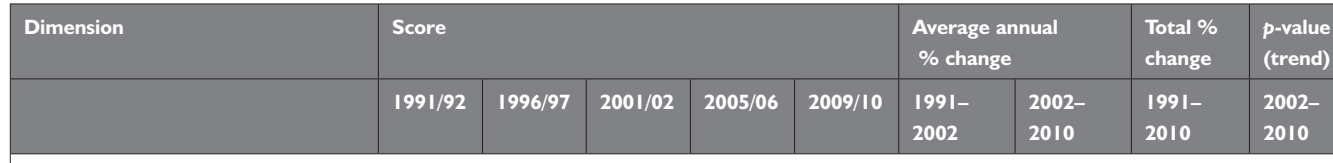

\section{First-contact care}

\section{Access outside office hours}

\begin{tabular}{|c|c|c|c|c|c|c|c|c|c|}
\hline$\%$ billing outside office hours & 95.8 & 90.9 & 79.4 & 68.8 & 58.9 & $-2.1 \%$ & $-3.7 \%$ & $-38.5 \%$ & $<0.001$ \\
\hline \multicolumn{10}{|c|}{ Services in alternative settings } \\
\hline$\%$ in homes & 92.3 & 87.9 & 76.2 & 67.5 & 55.3 & & & & \\
\hline$\%$ in nursing homes & 74.7 & 71.5 & 69.8 & 64.9 & 57.7 & & & & \\
\hline$\%$ in hospital (ER) & 85.4 & 79.2 & 64.7 & 52.3 & 41.9 & & & & \\
\hline$\%$ in hospital (non-ER) & 99.3 & 98.4 & 91.7 & 86.5 & 82.6 & & & & \\
\hline$\%$ in office only & 0.5 & 0.9 & 4.9 & 8.0 & 10.5 & & & & \\
\hline$\%$ in all four settings & 64.6 & 58.7 & 45.8 & 34.7 & 22.6 & & & & \\
\hline Mean score & 87.9 & 84.2 & 75.6 & 67.8 & 59.4 & $-1.7 \%$ & $-3.0 \%$ & $-32.5 \%$ & $<0.001$ \\
\hline
\end{tabular}

\section{Long-term person-focused care}

\section{Continuity}

\begin{tabular}{|l|l|l|l|l|l|l|l|l|l|l|l|}
\hline \% MSOC patients & 45.8 & 41.2 & 40.2 & 38.1 & 36.6 & $-1.4 \%$ & $-1.2 \%$ & $-20.0 \%$ & $<0.001$ \\
\hline Coordinated care \\
\hline \% patients seeing <4 physicians & 67.6 & 63.0 & 61.2 & 58.0 & 55.8 & $-1.1 \%$ & $-1.2 \%$ & $-17.5 \%$ & $<0.001$ \\
\hline
\end{tabular}

\section{Comprehensive for most health needs}

Service for both acute and chronic conditions

\begin{tabular}{|c|c|c|c|c|c|c|c|c|c|}
\hline Mean \% chronic contacts & 23.7 & 24.5 & 27.2 & 29.0 & 30.8 & & & & \\
\hline Mean \% acute contacts & 36.5 & 34.7 & 31.1 & 30.7 & 29.7 & & & & \\
\hline Mean score & 58.2 & 61.0 & 64.8 & 65.4 & 64.5 & $1.2 \%$ & $-0.1 \%$ & $10.9 \%$ & 0.988 \\
\hline
\end{tabular}

\section{Maternity care}

\begin{tabular}{|c|c|c|c|c|c|c|c|c|c|}
\hline$\%$ no obstetrical/maternity & 13.3 & 16.7 & 26.0 & 33.5 & 39.3 & & & & \\
\hline$\%$ pre-/postnatal and delivery & 66.8 & 52.2 & 31.4 & 23.8 & 20.5 & & & & \\
\hline Mean score & 76.7 & 67.8 & 52.7 & 45.2 & 40.6 & $-4.1 \%$ & $-3.2 \%$ & $-47.1 \%$ & $<0.001$ \\
\hline \multicolumn{10}{|l|}{ Mental healthcare } \\
\hline$\%$ with mental health contacts & 98.0 & 97.8 & 98.1 & 98.3 & 98.9 & $0.0 \%$ & $0.1 \%$ & $1.0 \%$ & 0.989 \\
\hline \multicolumn{10}{|l|}{ Geriatric care } \\
\hline$\%$ with "usual patients" aged $75+$ & 94.4 & 94.7 & 93.0 & 92.2 & 90.9 & $-0.2 \%$ & $-0.3 \%$ & $-3.7 \%$ & 0.002 \\
\hline \multicolumn{10}{|l|}{ Reproductive care } \\
\hline $\begin{array}{l}\text { Female patients (aged I8-74) } \\
\text { receiving pelvic exams }\end{array}$ & 23.5 & 23.4 & 25.0 & 26.1 & 25.0 & $0.7 \%$ & $0.0 \%$ & $6.4 \%$ & 0.959 \\
\hline \multicolumn{10}{|l|}{ Disease prevention } \\
\hline $\begin{array}{l}\text { Patients (aged 18-74) receiving } \\
\text { screening tests }\end{array}$ & 39.4 & 42.5 & 56.7 & 60.6 & 61.0 & $4.1 \%$ & $0.9 \%$ & $54.9 \%$ & 0.998 \\
\hline Overall summary score & 67.6 & 64.1 & 61.0 & 57.2 & 53.7 & $-1.1 \%$ & $-1.6 \%$ & $-20.5 \%$ & $<0.001$ \\
\hline
\end{tabular}

* Weighted average of individual dimension scores (equal weighting of 0.25 for each of first-contact care, long-term person-focused care, coordinated care and comprehensive for most health needs) 
We found marked reductions in most dimensions of full-service family practice (Table 4). The overall summary score fell over $20 \%$ across the study years $(p<0.001)$. The average annual percentage change between 2001/02 and 2009/10, the period of primary care investment, was slightly larger (-1.6\%) than between 1991/92 and 2001/02 (1.1\%).

The percentage of primary care physicians providing care outside of office hours fell from $95.8 \%$ in $1991 / 92$ to $58.9 \%$ in $2009 / 10$. Physicians providing care in all four out-of-office settings (emergency care in hospital, other hospital, home, long-term care facility) fell from $64.6 \%$ to $22.6 \%$. The average percentage of patients for whom physicians were the majority source of care fell from $45.8 \%$ to $36.6 \%$. The percentage of patients who received care from fewer than four unique primary care physicians fell from 67.6 to 55.8. All these declines were statistically significant at $p<0.001$ and persisted throughout the study period.

On dimensions reflecting comprehensiveness of care, trends were more varied (Table 4). The percentage of primary care physicians providing pre- and postnatal care and also performing deliveries fell from $66.8 \%$ to $20.5 \%$, while the percentage performing no maternity care rose from $13.3 \%$ to $29.3 \%$. There was a slight reduction in physicians acting as the usual provider of care to patients aged 75 and over (94.4\% to 90.9\%). Pap testing, glucose screening and lipids screening increased slightly over the study period, as did care for chronic relative to acute conditions. However, increases were greatest in the period preceding reform and did not reach statistical significance.

Summary scores varied significantly based on physician characteristics $(p<0.001$ for all examined variables; only 2009/10 significance tests reported (Table 5). On average, scores were higher among male physicians, though total percentage of change was almost equal for both sexes (-20.1\% female, $-20.0 \%$ male). While scores are lowest among the youngest and oldest physicians, declines were observed among all age groups. Physicians graduating from BC medical schools had slightly higher scores in all years, and a smaller total percentage change than graduates from elsewhere in Canada or international graduates $(-18.7 \%$ for UBC graduates compared to $-21.4 \%$ for other Canadian graduates, and $-21.1 \%$ for international graduates). While in 1991/92 scores were fairly constant across health authorities (if anything, higher in more urban Vancouver Coastal, Fraser Valley and Vancouver Island health authorities), declines were more rapid in these more urbanized areas, and so by 2009/10 the predominantly rural Interior and Northern health authorities had higher average scores. 
Full-Service Family Practice in British Columbia: Policy Interventions and Trends in Practice, $1991-2010$

TABLE 5. Mean full-service family practice score by physician characteristics

\begin{tabular}{|c|c|c|c|c|c|c|c|c|}
\hline & \multicolumn{5}{|c|}{ Summary score } & \multirow{2}{*}{$\begin{array}{l}\begin{array}{l}\text { Total \% } \\
\text { change }\end{array} \\
1991 / 92- \\
2009 / 10\end{array}$} & \multirow{2}{*}{$\begin{array}{l}\text { p-value } \\
\text { (trend) }\end{array}$} & \multirow{2}{*}{\begin{tabular}{|l} 
p-value \\
(ANOVA \\
across \\
groups)
\end{tabular}} \\
\hline & $1991 / 92$ & $1996 / 97$ & $2001 / 02$ & $2005 / 06$ & $2009 / 10$ & & & \\
\hline \multicolumn{9}{|l|}{ Gender } \\
\hline Female & 65.4 & 62.8 & 59.2 & 55.3 & 52.2 & $-20.1 \%$ & $<0.001$ & $<0.001$ \\
\hline Male & 68.2 & 64.6 & 61.7 & 58.1 & 54.6 & $-20.0 \%$ & $<0.001$ & \\
\hline \multicolumn{9}{|l|}{ Age group } \\
\hline 39 and under & 63.9 & 60.0 & 56.5 & 52.4 & 50.6 & $-20.9 \%$ & $<0.001$ & $<0.001$ \\
\hline 40-44 & 69.3 & 65.5 & 61.3 & 57.6 & 52.7 & $-23.9 \%$ & $<0.001$ & \\
\hline $45-49$ & 69.5 & 67.1 & 63.0 & 58.2 & 55.2 & $-20.5 \%$ & $<0.001$ & \\
\hline $50-54$ & 70.8 & 66.9 & 64.4 & 59.9 & 55.2 & $-22.0 \%$ & $<0.001$ & \\
\hline $55-59$ & 71.4 & 66.9 & 63.9 & 59.7 & 56.8 & $-20.5 \%$ & $<0.001$ & \\
\hline $60-64$ & 71.6 & 67.6 & 61.4 & 58.4 & 54.0 & $-24.6 \%$ & $<0.001$ & \\
\hline $65+$ & 68.3 & 61.1 & 57.1 & 52.3 & 49.8 & $-27.2 \%$ & $<0.001$ & \\
\hline \multicolumn{9}{|l|}{ Years in practice } \\
\hline$<5$ & 59.2 & 55.7 & 50.7 & 49.2 & 47.3 & $-20.0 \%$ & $<0.001$ & $<0.001$ \\
\hline $6-10$ & 66.1 & 61.0 & 56.8 & 53.3 & 51.1 & $-22.6 \%$ & $<0.001$ & \\
\hline $1 \mid-20$ & 69.1 & 65.4 & 61.4 & 56.9 & 52.7 & $-23.7 \%$ & $<0.001$ & \\
\hline $21-30$ & 70.0 & 66.9 & 63.6 & 59.6 & 55.9 & $-20.2 \%$ & $<0.001$ & \\
\hline $31+$ & 70.9 & 65.9 & 61.8 & 57.7 & 53.7 & $-24.2 \%$ & $<0.001$ & \\
\hline \multicolumn{9}{|l|}{ Place of graduation } \\
\hline UBC & 68.4 & 65.3 & 62.7 & 59.4 & 55.6 & $-18.7 \%$ & $<0.001$ & $<0.001$ \\
\hline Other Canadian school & 66.4 & 62.9 & 59.6 & 55.5 & 52.2 & $-21.4 \%$ & $<0.001$ & \\
\hline International & 68.2 & 64.5 & 60.9 & 57.6 & 53.8 & $-21.1 \%$ & $<0.001$ & \\
\hline \multicolumn{9}{|l|}{ Health authority } \\
\hline Vancouver Coastal & 68.3 & 64.3 & 60.6 & 57.1 & 52.6 & $-23.1 \%$ & $<0.001$ & $<0.001$ \\
\hline Fraser Valley & 67.8 & 62.7 & 59.2 & 55.1 & 51.7 & $-23.8 \%$ & $<0.001$ & \\
\hline Vancouver Island & 67.5 & 65.2 & 62.0 & 57.6 & 53.2 & $-21.2 \%$ & $<0.001$ & \\
\hline Interior & 66.9 & 64.6 & 62.3 & 58.8 & 57.2 & $-14.5 \%$ & $<0.001$ & \\
\hline Northern & 66.1 & 64.0 & 63.7 & 61.7 & 59.0 & $-10.8 \%$ & $<0.001$ & \\
\hline
\end{tabular}

Note: Data were missing for some physician characteristics. Gender: I missing in 2009/I0. Age: I missing in 2005/06. Years in practice: I missing in 1991/92 and 200 I/02, 44 in 2005/06. Place of graduation: 43 missing in 2005/06, 59 in 2009/10. Health authority: I6 missing in 1991/92, 18 in 1996/97, 24 in 200 I/02, 13 in 2005/06 and 5 in 2009/10.

In both scenarios of sensitivity analyses (first assuming that all physicians excluded with APP billings or low billings would have had scores of 100 , and then that all physicians excluded for any reason would have had scores of 100), significant declines were still observed (see Appendix). As expected, the magnitude was smaller $(-15.8 \%, p<0.001$ with low/APP billers $=100 ;-9.1 \%, p=0.001$ with all excluded $=100$ ). 


\section{Discussion}

Over the past decade, Canadian provinces have implemented major reforms in primary care policy. It is estimated that more than $\$ 1$ billion has been invested in primary care reform in British Columbia (GPSC 2012). Pre-existing trends in practice patterns in the province have not changed following these investments, though we do not know what would have happened in the absence of reform. We found major declines in most dimensions of "full-service family practice." Significant declines are seen among all physician groups, but differences in practice patterns remain across age groups, sex of practitioner and health authority, findings consistent with previous studies (Glazier et al. 2009; Hutten-Czapski et al. 2004). This lack of change coincides with an approximately $\$ 20,000$ increase in average (fee-adjusted) billings observed between 2001/02 and 2009/10, the period during which incentive payments were introduced.

As with any analysis of administrative claims data, our study has limitations, especially pertaining to the measurement of practice patterns (and given the need to find comparable measures across study years). For example, we could measure only relational continuity with an individual provider (Haggerty et al. 2003) and the provision of services in the context of individual physician-patient pairs. Some (an unknown number of) BC primary care physicians do practise in groups and share in the care of patients. The individual patient-physician dyads, however, are the focus of British Columbia's reform efforts. While relevant to the province's policy environment, this focus does limit generalizability. We could also examine only the presence or absence of care as indicated in fee-for-service records (care outside office hours, in alternative settings, maternity, mental health, reproductive care and preventive screening). We could not assess quality, nor could we examine health-risk assessment, patient education, record keeping or use of information technology.

A threat to the validity of our findings is that fee-for-service data do not completely capture services provided. Our sensitivity analysis is extremely conservative, and we do not believe it is possible that a shift to alternative payment schemes can account for the changes we observed. While in other provinces primary care reform was accompanied by new funding models implemented provincewide, this is not the case in British Columbia. A small subset of physicians do not bill fee-for-service, but these are unique instances, often with special populations (e.g., Vancouver's Downtown Eastside) or specific geographic areas (e.g., some northern communities), and these physicians would not be providing care to patients who normally see doctors on a fee-for-service basis. No policy developments or funding arrangements have arisen that would have offset the fee-for-service declines observed, nor has there been support for other health professionals to provide primary care services previously provided by fee-forservice physicians.

We also examined the BC results of the National Physician Survey (NPS 2004, 2010). Consistent with our findings, the percentage of physicians reporting they work in hospitals, emergency departments and nursing homes fell between 2004 (the earliest year available) and 2010 (56.7\% to $54.7 \%$ for hospitals, $23.1 \%$ to $21.2 \%$ for emergency departments and $32.9 \%$ to 
Full-Service Family Practice in British Columbia: Policy Interventions and Trends in Practice, 1991-2010

$23.6 \%$ for nursing homes). The percentage providing intrapartum care also fell between 2004 and 2010 , from $18 \%$ to $12.9 \%$. For all dimensions where there were comparable measures on the 2010 NPS (provision of services in hospitals, emergency departments and nursing homes; provision of intrapartum care; provision of care for patients aged 75+; provision of care for patients with mental illness), we found higher percentages based on 2009/10 administrative data. This finding may be due in part to our exclusion criteria, which removed from analysis physicians who were not likely to be in regular community practice, but it provides reassurance that we have not systematically undercaptured service provision. Differences may be present also because the NPS has a low and declining response rate of $35.2 \%$ in 2004 and $17.8 \%$ in 2010. In addition, the NPS provides some information on dimensions we were unable to capture administratively. In 2010, 50.5\% of NPS reported offering palliative medicine, up from $41.4 \%$ in 2004. Also in 2010, 54.2\% reported using electronic records (either alone or in combination with paper), though comparable data were not available in 2004.

The construction of the scoring and index used in this analysis is, by definition, arbitrary. We used Starfield's accepted definition of care to frame our approach but still made many decisions about measurement and scoring. Whatever limitations exist in this approach, they were at the very least consistently applied across all years and therefore cannot explain the trends observed.

British Columbias primary care reform efforts were predicated on the idea that the doctor-patient dyad is central to the provision of primary care, and that improvements could be made through "operational" modifications to the existing fee-for-service payment system. The full rationale for this policy direction is uncertain and has not been defended. Cited reasons for discarding team-based models, namely, the fact that physicians were not trained to work in teams and that these models may not be well suited to sparsely populated areas (Mazowita and Cavers 2011; Tregillus and Cavers 2011), are neither unique to British Columbia nor insurmountable. It is perhaps also worth noting that reform efforts were managed, in large part, by the BC Medical Association (now Doctors BC), which may explain the physician focus.

Trends should give policy makers pause that the overarching objective of promoting fullservice family practice has not been achieved. The present analysis reveals that the full range of services outlined as part of full-service family practice is no longer being provided within the context of the doctor-patient dyad. Reform efforts did not forestall or reverse these changes (as of 2009/10), calling into question whether this "operational" approach has achieved the transformative change that has been claimed elsewhere (Cavers et al. 2010; Mazowita and Cavers 2011). More focused examination of the impact of individual components of British Columbia's primary care reform on relevant patient-level outcomes is still needed. This should include incentive payments as well as other features of reform, the effects of which might only now be visible. 
Correspondence may be directed to: M. Ruth Lavergne, Centre for Health Services and Policy Research, School of Population and Public Health, Faculty of Medicine, University of British Columbia, 201 - 2206 East Mall, Vancouver, BC V6T 1Z3; e-mail: rlavergne@chspr.ubc.ca

\section{References}

British Columbia Ministry of Health [creator] (2012): Consolidation File (MSP Registration \& Premium Billing). Population Data BC [publisher]. Data Extract. MOH (2011). <http://www.popdata.bc.ca/data>.

British Columbia Ministry of Health [creator] (2013a): Medical Services Plan (MSP) Payment Information File. Population Data BC [publisher]. Data Extract. MOH (2011). <http://www.popdata.bc.ca/data>.

British Columbia Ministry of Health [creator] (2013b): Discharge Abstract Database (Hospital Separations). Population Data BC [publisher]. Data Extract. MOH (2011). <http://www.popdata.bc.ca/data >.

Burge, F., J. Haggerty, R. Pineault, M.-D. Beaulieu, J.-F. Lévesque, C. Beaulieu et al. 2011. “Relational Continuity from the Patient Perspective: Comparison of Primary Healthcare Evaluation Instruments." Healthcare Policy 7 (Special Issue): 124-38.

Canadian Institute for Health Information (CIHI). 2012. Supply, Distribution and Migration of Canadian Physicians, 2011. Ottawa: Author. Retrieved April 3, 2014. < https://secure.cihi.ca/estore/productFamily.htm?pf= PFC1968\&lang $=$ en \&media $=0>$.

Cavers, W., V. Tregillus, A. Micco and M. Hollander. 2010."Transforming Family Practice in British Columbia." Canadian Family Physician 56(12): 1318-21.

Chan, B. 2002."The Declining Comprehensiveness of Primary Care." Canadian Medical Association Journal 166(4): 429-34.

CMA Bulletin. 2011. “Attitudes of New MDs Mean Medicine Is in for a Change: Survey." Retrieved April 3, 2014. $<$ https://www.cma.ca/multimedia/CMA/Content_Images/Policy_Advocacy/Policy_Research/22-Bulletinnov22-rev.pdf $>$.

Crossley, T., J. Hurley and S. Jeon. 2009. "Physician Labour Supply in Canada: A Cohort Analysis." Health Economics 18(4): 437-56. doi: 10.1002/hec.1378.

General Practice Services Committee (GPSC). 2009.“Backgrounders." Retrieved April 3, 2014.

$<$ http://www.gpscbc.ca/media/backgrounders $>$.

General Practice Services Committee (GPSC). 2012. 2011/2012 Annual Report. Vancouver: BC Ministry of Health and BC Medical Association.

General Practice Services Committee (GPSC) and BC Ministry of Health. 2010. “Frequently Asked Questions - Full Service Family Practice Incentive Program. Legislation and Governance of the Medical Services Plan." Retrieved April 3, 2014. <http://www.health.gov.bc.ca/msp/legislation/bcmaagree_faqs_fsfp.html>.

Glazier, R., J. Klein-Geltink, A. Kopp and L. Sibley. 2009. "Capitation and Enhanced Fee-for-Service Models for Primary Care Reform: A Population-Based Evaluation." Canadian Medical Association Journal 180(11): E72-81. doi: $10.1503 / \mathrm{cmaj} .081316$.

Haggerty, J. 2008. “Practice Features Associated with Patient-Reported Accessibility, Continuity and Coordination of Primary Health Care." Annals of Family Medicine 116-123. doi: 10.1370/afm.802.

Haggerty, J., F. Burge, J. Lévesque and D. Santor. 2007. “Operational Definitions of Attributes of Primary Health Care: Consensus among Canadian Experts." Annals of Family Medicine 5(4): 336-44. doi: 10.1370/afm.682.

Haggerty, J., R. Reid, G. Freeman, B. Starfield, C. Adair and R. McKendry. 2003. “Continuity of Care: A Multidisciplinary Review. British Medical Journal 327(7425): 1219-21. doi: 10.1136/bmj.327.7425.1219. 
Full-Service Family Practice in British Columbia: Policy Interventions and Trends in Practice, 1991-2010

Hutchison, B., J.-F. Lévesque, E. Strumpf and N. Coyle. 2011.“Primary Health Care in Canada: Systems in Motion." Milbank Quarterly 89(2): 256-88. doi: 10.1111/j.1468-0009.2011.00628.x.

Hutten-Czapski, P., R. Pitblado and S. Slade. 2004. "Short Report: Scope of Family Practice in Rural and Urban Settings." Canadian Family Physician 50: 1548-50.

Kazanjian, A., R. Reid, N. Pagliccia, L. Apland and L. Wood. 2000. Issues in Physician Resources Planning in BC: Key Determinants of Supply and Distribution, 1991-96. Vancouver: Centre for Health Services and Policy Research. Lavergne, M., K. McGrail, S. Peterson, S. Sivananthan, R. McKendry and D. Mooney. 2013.“Defining and Measuring 'Full-Service' Family Practice in British Columbia." Vancouver: Centre for Health Services and Policy Research. Retrieved April 3, 2014.<http://www.chspr.ubc.ca/sites/default/files/publication_files/WP_Lavergne_ FSFP.pdf $>$.

Mazowita, G. and W.J. Cavers. 2011.“Issues in International Health Policy: Reviving Full-Service Family Practice in British Columbia." New York: The Commonwealth Fund. Retrieved April 3, 2014. <http://www.commonwealthfund.org/Publications/Issue-Briefs/2011/Aug/Reviving-Full-Service-Family-Practice-in-British-Columbia. aspx>.

National Physician Survey (NPS). 2004."2004 Physicians by Province." Retrieved April 3, 2014. <http://nationalphysiciansurvey.ca/result/2004-physicians-by-province/>.

National Physician Survey (NPS). 2010. “2010 Results for British Columbia." Retrieved April 3, 2014. <http:// nationalphysiciansurvey.ca/result/2010-bc/>.

Olatunde, S., E. Leduc and J. Berkowitz. 2007.“Different Practice Patterns of Rural and Urban General Practitioners Are Predicted by the General Practice Rurality Index." Canadian Journal of Rural Medicine 12(2): 73-80.

Starfield, B. 1998. Primary Care: Balancing Health Needs, Services and Technology. New York: Oxford University Press.

Starfield, B. 2008. "Primary Care in Canada: Coming or Going?" Healthcare Papers 8(2): 58-62.

Starfield, B., L. Shi and J. Macinko. 2005. "Contribution of Primary Care to Health Systems and Health." Milbank Quarterly 83(3): 457-502. doi: 10.1111/j.1468-0009.2005.00409.x.

Tregillus, V. and W. Cavers. 2011. “General Practice Services Committee: Improving Primary Care for BC Physicians and Patients." Healthcare Quarterly 14 (Special Issue): 1-6.

Watson, D., S. Slade, L. Buske and J. Tepper. 2006. “Intergenerational Differences in Workloads among Primary Care Physicians: A Ten-Year, Population-Based Study." Health Affairs 25(6): 1620-28. doi: 10.1377/ hlthaff.25.6.1620.

Wong, E. and M. Stewart. 2010. "Predicting the Scope of Practice of Family Physicians." Canadian Family Physician 56(6): e219-25. 